\title{
Trilhas na batalha dos cartazes ${ }^{1}$
}

\author{
Ercio Sena
}

1 A primeira versão deste texto foi apresentada no seminário A visibilidade dos anônimos, promovido pelo Grupo de Pesquisa Mídia e Narrativa, da Pontifícia Universidade Católica de Minas Gerais (PUC-MG), em Belo Horizonte, nos dias 06 e 07 de novembro de 2013. 


\section{Resumo}

O trabalho pretende discutir as escolhas e os rumos do movimento social conhecido como "As jornadas de junho". Com o objetivo de mostrar as principais propostas dos movimentos sociais ocorridos no Brasil ao longo desse mês, no ano de 2013, duas grandes manifestações em Belo Horizonte são analisadas. Em uma delas, os cartazes dos manifestantes são tomados como referência das propostas que motivaram e deram sustentação às causas dos manifestantes.

Palavras-chave

Comunicação, manifestação, cartazes.

\section{Abstract}

This paper discusses the choices and the direction of the social movement known as "The journeys of june". In order to show the main proposals of social movements in Brazil during that month, in 2013, two large demonstrations in Belo Horizonte are analyzed. In one of them posters are taken as reference of proposals that have motivated and supported the cause of the demonstrators.

\section{Keywords}

Communication, demonstrations, posters. 
Depois de atender de forma surpreendente ao apelo do Movimento Passe Livre (MPL), que contestou o aumento da tarifa do transporte público, as manifestações, conhecidas como as jornadas de junho, tendo sido iniciadas em São Paulo, o centro político e econômico mais ativo do Brasil, alastraramse para outras cidades. Logo que começaram os protestos, a perplexidade se instalou diante da ausência de análises que pudessem pelo menos indicar o comando e a direção que os movimentos tomariam. Falas de algumas lideranças do Partido dos Trabalhadores se confundiram com o posicionamento da mídia e, nos primeiros momentos, não foi raro observar líderes de oposição e governo em confronto verbal com manifestantes.

Aos poucos um novo quadro foi se delineando e as forças políticas optaram por se posicionar, pelo menos formalmente, ao lado das manifestações, sem apoiar os chamados atos de vandalismos. Assim que as manifestações tomaram conta do país, várias perguntas se colocaram. Quais são os problemas que afligem e fazem esse contingente humano protestar? O que querem? A quem responsabilizam? Quem são seus líderes? A quem se deve ouvir e com quem negociar? Embora essas questões desafiassem intelectuais, governo e meios de comunicação, grupos organizados da sociedade brasileira passaram imediatamente a disputar os sentidos que dariam curso às grandes mobilizações.

Em meio à pluralidade de vozes que se inscreveu neste debate, também fizemos nossa aposta. Na dúvida entre sobre os cenários que se configurariam, entendemos que a sensatez recomendava olhar de perto a rebeldia popular. A referência de mobilizações anteriores (Diretas Já, Lula Lá, Fora Collor), dadas as suas diferenças, não garantia uma zona de conforto para analisar os desdobramentos das novas ações. Quem levaria vantagem com a presença dos atores inesperados no jogo político? Os movimentos massivos que se expressavam, além de plurais, sem personalidades dirigentes, não estavam controlados por um centro hegemônico. Era uma atuação concatenada de anônimos. Com pluralidade e diferenças se afirmou a força gregária das jornadas de junho, na dispersão dos cartazes e na polifonia de reivindicações e protestos, a multidão ocupava as ruas das maiores cidades do país. 
Um desafio estimulou a inserção nos trajetos das passeatas. Havia várias trilhas para as quais o movimento apontava. Protestos animavam críticas à política de saúde pública, ao congresso nacional, às figuras de expressão pública, aos transportes, à educação, à liberdade de expressão, outros, bem humorados, pediam a volta da tomada de dois pinos e ajudavam a constituir um mosaico de reivindicações gerais em trilhas diversas que pareciam diluir e fragmentar a ação coletiva. Como aponta Jacques Rancière (2012), a política ocupava-se do que era dado a ver, do que seria dito sobre o que foi visto e, obviamente, da qualidade desse dizer e das condições existentes no complexo jogo político. Em meio à disputa que se colocou na construção de sentidos desses movimentos, era necessário encontrar uma trincheira para expressar as falas de uma história que prosseguia nas jornadas de junho. Haveria eixos a unir e sustentar as diferenças expressas pelos cartazes? Ou a força gregária do movimento era negar tudo o que aí está? Em Belo Horizonte acompanhei as duas maiores passeatas. Na primeira, 120 mil pessoas, de acordo com a Polícia Militar e jornais locais, percorreram cerca de 12 quilômetros entre o centro da cidade até as proximidades do Mineirão. Na segunda, no dia 26, cerca de 60 mil pessoas, no feriado municipal decretado para esvaziar a passeata, fizeram o mesmo trajeto, dia também em que a seleção brasileira enfrentava a seleção do Uruguai na cidade.

\section{A configuração do espaço da manifestação}

A concentração dos manifestantes, no dia 26, aconteceu na Praça 7, ponto central de Belo Horizonte. Por lá foi possível observar grupos em disputa para afirmar as propostas e a identidade da manifestação, a atuar e preparar a encenação na passeata marcada para o meio dia. Militantes de partidos políticos e organizações estudantis disputavam as palavras de ordem que comandariam o movimento. O conflito entre os defensores dos partidos políticos e outros que eram contrários à participação deles foi vencido pelos primeiros. As bandeiras de partidos de esquerda e de entidades estudantis, em número menor do que o habitual se fizeram presentes. Estudantes libertários, jovens de classe 
média, anarquistas, novos trabalhadores, moradores de rua, jovens da periferia, autônomos, extremistas e, quem sabe, até "semimarginais" compunham a paisagem múltipla de uma concentração eclética, diferenciada. Reivindicações ligadas à melhoria de serviços públicos e acesso aos bens de consumo relembravam a paisagem comum em movimentações observadas nas últimas décadas. Era evidente que o acesso aos bens ou a liberdade que a sociedade, de alguma forma, estimula, parecia interditado para aquelas pessoas.

A escolha de uma saída coletiva, no entanto, não apagou as diferenças, pelo contrário, elas estavam nítidas na paisagem que preparava a grande passeata e na disposição dos agentes políticos tornarem visíveis as direções de suas escolhas. Dessa vez, a presença da multidão impediria que os meios de comunicação ignorassem suas propostas e, por horas e dias, a pauta de quase todos esteve voltada para a cobertura das manifestações. Mas não apenas isso, também os meios, a cobertura, os modos de tratar a notícia e a cultura seriam alvo do inconformismo dos anônimos em movimento. A desconfiança da cobertura da mídia gerou reações enérgicas contra as emissoras de televisão e estimulou a realização de reportagens alternativas de grupos que se associaram para produzir notícias diretamente das manifestações. Tanto a opinião publicada como a forma de selecionar os conteúdos nos meios de comunicação foi criticada. Não é exagero dizer que também a democratização dos meios de comunicação se tornou demanda relevante nos movimentos de junho.

A experiência desses sujeitos alterou a paisagem das ruas centrais da cidade. Contrariando as recentes normas de ocupação dos espaços públicos aprovadas pelo poder público municipal, os populares exibiram suas condições, expressaram seu desconforto e deram transparência a sua experiência, até então desconhecida, ausente da ciência coletiva em função de sua invisibilidade midiática. Na diversidade do movimento não era possível a nenhum olhar captar toda riqueza de situações que se apresentava simultaneamente.

Novas expectativas de direitos estimulava o surgimento de sujeitos na cena pública. Agora, eles ocupavam os espaços e colocavam suas pautas na ordem do dia. Boaventura Sousa Santos (2007), ao criticar as formas impostas de poder e 
saber, principalmente em sociedades do sul, defende uma democracia radical de alta intensidade. Para o sociólogo, as relações de poder devem ser substituídas por relações de autoridade compartilhada. Acrescenta que é necessário criar novas relações entre os princípios de igualdade e diferença. Ao analisar os movimentos emancipatórios ocidentais, mostra que a orientação teórica deles esteve voltada para o princípio da igualdade, não para o reconhecimento das diferenças. As diferenças, no entanto, era o que surpreendia nas jornadas de junho, turvavam a inteligibilidade e, ao mesmo tempo, ascendiam, inflamavam e davam energia ao movimento. A unidade, impossível de ser alcançada na pauta de reivindicações, se construiu no método: uma voz não poderia representar todos, a afirmação da diferença levava à afirmação dos cartazes, das bandeiras, uma por uma, a instituir o sentido da ação dos anônimos que formavam a multidão.

Durante a concentração para a passeata pessoas se posicionavam em lugares de maior fluxo portando cartazes à espera da aprovação de leitores desconhecidos que transitavam próximos da aglomeração. Era possível observar militantes experientes, com maior traquejo, buscar um tipo de ordenação e orientação para a saída da passeata. Porém, dessa vez, não havia direção única, nem um instrumento capaz de organizar a pluralidade num só corpo, numa só voz. Palavras de ordem contra a polícia, governos estadual e municipal ganhavam parcela da multidão. Contra a presidenta Dilma, insatisfações reivindicavam o veto do ato médico, a não construção da usina de Belo Monte, entre outros.

Na preparação para a passeata um grupo de ativistas se mobilizou para produzir cartazes e deixa-los à disposição dos manifestantes. Os cartazes se firmaram como expressão das manifestações, mas o número de pessoas que os levavam era bem menor do que o número de manifestantes. A iniciativa do grupo que espalhou cartazes entre a multidão indicava disposição de instituir sentidos democráticos à manifestação. Através deles se afirmava as tradicionais reivindicações por saúde, educação, melhoria nos transportes, mas também se enfatizava a reforma política, a democracia justa e igualitária, o direito dos moradores de rua, exortando reacionários e liberais a saírem do movimento. 


\section{A expressão dos anônimos nos cartazes}

Manifestações também são preparadas como grandes festas. Nessa celebração, observada de longe, não se podia identificar as causas da movimentação, mas era possível perceber sintomas incômodos de inúmeras recusas e demandas abrigadas em palavras de ordem e cartazes. Em trabalho realizado anteriormente sobre os cartazes alusivos à Revolução dos Cravos, Gomes (2011) analisa as informações visuais, fontes de propaganda políticoideológica, assim como o valor estético dos cartazes do Museu Nacional de Imprensa de Lisboa para retomar a celebração revolucionária. Os cartazes são refletidos como narrativas do acontecimento. Por esse trabalho, o autor pretende aproximar o leitor do contexto anunciado na publicidade dos cartazes. Destaca o colorido da revolução, a assinatura de importantes artistas, aliados do movimento revolucionário, mas também profissionais anônimos, responsáveis pela produção de cartazes em oficinas de artes gráficas. O autor toma o cartaz como mediador entre a obra e seu efeito transformador. Pode-se considerar que o intento expresso neles é o de associar a arte aos efeitos transformadores de uma ordem que a revolução pretendia ultrapassar.

Se a estética voltada para a reflexão da beleza sensível e do fenômeno artístico não era o que marcava principalmente a confecção dos cartazes nas jornadas de junho, é possível afirmar que uma nova estética foi formada na mediação das imagens que se produziu em diversas construções narrativas desses movimentos. Assim como na perspectiva apontada por Rancière (2012), pode-se dizer que a estética dos cartazes diz respeito aos meios de dispor um pensamento, um sistema de formas para autorizar novas falas no jogo político. A invisibilidade dos anônimos, evidenciada e empunhada por eles, destacava letras pouco apreciáveis, porém marcadas pela experiência e produção própria do efeito de verdade. Não a verdade traduzida por porta-vozes, mas a verdade possível, mediada pela expressão limitada dos cartazes escritos à mão em folhas de cartolina. No confronto das alteridades, diferenças caminhavam lado a lado. O outro, a quem se combatia, poderia não estar ali representado e, por vezes, 
nem era identificado nitidamente nos cartazes. O adversário também poderia ser a cultura ou mesmo às represálias que obstruíam às incontáveis reivindicações e recusas dos anseios da multidão em ação.

O discurso dos cartazes trouxe também a dimensão retórica, na medida em que podem ser tomados como a expressão de uma linguagem direta voltada para uma ação de mudança de direção ou influência, atitude ou valor como aponta Silverstone (2002) ao definir o uso midiático da retórica. As falas dos movimentos reivindicatórios, em geral, são retóricas porque querem convencer, reconhecem as diferenças de opiniões e são argumentativas, pois visam mudar atitudes, pontos de vista e comportamentos. A audiência era o objetivo mais importante a ser alcançado com o gesto dos manifestantes. O desafio era também narrar histórias, experiências e anseios para encontrar respostas.

Trazer a expressão dos cartazes para discussão foi outro desafio que se colocou ao longo daquele percurso. Como classificá-los? Qual a direção que esta história poderia ter? Estava claro que não havia apenas um caminho, mas diferentes trilhas em um só movimento. O desejo de comunicação dos manifestantes era evidente, como decifrá-los num sentido?

Assim que essas questões se apresentaram, me pus a contar os cartazes a partir de uma classificação dicotômica e esquemática. Propostas de caráter democrático/popular e propostas excludentes, contrárias à participação popular. Sair a contar os cartazes não pareceu ideal, logo percebi que o modo de olhar poderia me afastar de uma avaliação isenta. Então, decidi parar em um ponto específico da Avenida Antônio Carlos e fazer uma contagem dos cartazes de acordo com uma ordem classificatória. É evidente que centenas de manifestantes, portando cartazes passaram pelo número 2.764 da avenida, mas o dever de isenção me permitiu contar e categorizar apenas os que passassem do lado direito do poste que estava a minha frente no canteiro central. Como o lugar da contagem dos cartazes era específico, isso me deu certo tempo para observar os cartazes que vinham nessa direção, classificá-los e, por vezes, anotá-los. Nesse local, permaneci por cerca de duas horas e meia. 
Os cartazes foram classificados em quatro tipos. Primeiramente, cartazes que traziam abordagens gerais, alusivas ao movimento, ao direito de manifestação e que destacavam insatisfação. Em segundo lugar, aqueles que tinham a crítica à corrupção como foco. Em seguida, os que abordavam conflitos distributivos e pediam melhoria dos serviços públicos: saúde, educação, transportes. E, por fim, os cartazes que traziam demandas por reconhecimento identitário e liberdade de expressão. A classificação refletia a hipótese de que esses temas, nesta ordem, seriam os mais explorados pelos manifestantes que carregavam seus cartazes na expectativa de difundir suas causas. Havia outras classificações possíveis, mas considerei que estas poderiam dialogar com as questões que motivaram vários debates sobre a natureza dos movimentos.

De um total de 231 cartazes identificados e analisados de acordo com a classificação proposta, 29 deles (cerca de 12,5\%) eram cartazes gerais, 27 cartazes (quase 12\%) eram críticos da corrupção na política, 125 (quase $55 \%$ ) deles estavam no campo dos conflitos distributivos, portanto, traziam reivindicações por saúde, educação, transportes, melhorias dos serviços públicos e, por fim, 50 cartazes (cerca de 22,5\%) traziam demandas por reconhecimento identitário e liberdade de expressão.

Nos cartazes gerais era possível observar a exaltação do movimento, além de manifestações contrárias a Federação Internacional de Futebol Associado (Fifa). "Não estamos na arquibancada, estamos virando o jogo". Por este cartaz se contesta o caráter passivo e acomodado dos brasileiros. A busca do lugar comum na metáfora do futebol inscreve e propõe uma nova compreensão sobre o papel dos anônimos. De espectadores do jogo político, agora, se colocam como jogadores, protagonistas desse novo espetáculo. Outros pediam o voto consciente.

"Isso é democracia, Legalize a liberdade", assinalavam outros cartazes, empenhados em defender a manifestação como forma de expressão mais adequada para fazer valer a opinião de sujeitos comuns. "É tanta coisa que não cabe num cartaz", era outra expressão que apontava o incômodo com a maior parte das experiências que são dadas a ver e conhecer. Por certo, a insatisfação 
geral com os assuntos públicos era a maior motivação daquele breve texto. "Odeio balas de borracha, Não a violência, Legalize o vinagre" eram outras expressões alusivas à ação da polícia em defesa do movimento, sem as frequentes ameaças associadas à presença do aparato repressivo.

Outro cartaz recuperava a autoestima do manifestante e de uma geração mal vista e mal falada por não agir nem defender seus direitos. Nele, o movimento era apresentado como prova que autorizava a louvação de si e de seus iguais. "Nunca tive tanto orgulho de ser brasileiro e de ter nascido nessa honrada geração".

Na crítica à corrupção um cartaz ameaçava, "Ou para a roubalheira ou paramos o Brasil". A palavra corrupção era grafada em sinal de igualdade com o crime hediondo num cartaz. Em outro, se destacava, "Cadeia para corruptos". Algumas vezes o discurso contra corrupção esteve orientado para o confronto das posições hegemônicas em disputa na política nacional. Em decorrência disso, um cartaz assinalava "Prisão imediata para mensaleiros". Na maior parte dos cartazes, no entanto, o que se viu foi um discurso genérico, procurando atingir políticos de maneira indiscriminada. No discurso que se orientava contra a corrupção pode se afirmar uma evidente insatisfação com o mundo político, mostrando o desgaste da repercussão pública sobre essa atividade.

No campo das reivindicações que expressavam conflitos distributivos um dos cartazes anunciava e justificava a presença do manifestante na praça, "Por você Paloma que esperou por uma cirurgia por 13 anos". Em outro, outra justificativa, "Por você minha mãe que trabalhou por 40 anos sem direito a aposentadoria". Ao mesmo tempo em que os direitos eram reclamados, a experiência de cada um era anunciada para acusar a falta e justificar a atitude individual e também o movimento. A expressão do cartaz era a forma tornar visível o drama pessoal e, portanto, de dar-Ihe importância pública.

A crítica ao sistema de saúde era feita na denúncia de um longo tempo de espera por uma cirurgia. No outro cartaz, o amor filial, o reconhecimento do esforço e da luta materna são os instrumentos que mobilizam e articulam a intervenção 
política manifestada. As diversas críticas à Fifa ou à subserviência do governo à entidade máxima do futebol foram formas de expressar o inconformismo com as prioridades dos investimentos, reclamando de maneira contundente mais cuidados com saúde, sem dúvida, dentre as bandeiras, a mais destacada.

"Não se faz copa com hospitais, nem se salva vidas com estádio", anunciava outro cartaz em resposta às declarações do ex-jogador Ronaldo Fenômeno. Em muitos cartazes em que a saúde era reclamada, as relações entre a copa do mundo e os investimentos na saúde eram comparadas. Foi possível observar também cartazes que criticavam o valor da energia elétrica e o preço das tarifas de ônibus. Na reivindicação dos transportes, a reposta aos interlocutores críticos do movimento, "Não é por 20 centavos, é por direitos".

A educação também apareceu de forma significativa em cartazes que exigiam qualidade e exaltavam a importância dos professores. "Professor te desejo um salário de deputado. Vendo ou troco a copa por um ensino de qualidade", anunciava um cartaz empenhado em destacar problemas vividos na educação. Ao reclamar a melhoria pela remuneração de professores e criticar os valores recebidos pelos deputados, outros cartazes, escritos com propositais erros ortográficos, denunciavam a má qualidade da educação no país. Em outro, o desenvolvimento econômico era associado à educação, "País desenvolvido, é país que tem educação como prioridade".

As demandas por reconhecimento identitário e liberdade de expressão eram trilhas apontadas em outro segmento de cartazes analisado. Por trás deles, a sugestão sobre demandas e sentidos poderia ser completada pelo leitor. O símbolo da Rede Globo foi associado à suástica nazista em alguns cartazes. Nesses cartazes, uns dos raros que puderam contar com produção gráfica de qualidade, eram anunciadas as insatisfações com o monopólio e a manipulação da opinião pública identificada na ação dos meios de comunicação de massa.

"Mais amor, menos pastor, Pastor vai pastar", eram cartazes que criticavam o deputado Marco Feliciano, sem dúvida, a figura pública mais hostilizada nas 
manifestações de BH. Em outro cartaz se afirmava, "Direitos das mulheres só existe no Estado laico. Fora Feliciano, liberdade para dentro do meu útero", bradavam cartazes em defesa de causas feministas em confronto direto com as posições da bancada evangélica, da qual o deputado tornou-se a figura mais conhecida. A maioria desses cartazes afirmou direitos homossexuais, rechaçando qualquer forma de discriminação para associar a figura do deputado Feliciano com o antagonismo da liberdade, dos direitos humanos e até da inteligência.

A ausência de liberdade de expressão e o controle da informação também eram alvo de cartazes que cobravam a atenção da mídia sobre crimes e ações violentas da polícia. "Quanta hipocrisia, na favela a polícia mata pobre todo dia, ninguém sabe, ninguém vê".

\section{Considerações finais}

Os cartazes na multidão constituíram imagens das mais representativas dos protestos de junho. Ao fazer uma breve contagem deles em uma das grandes manifestações que aconteceram no Brasil, não pretendemos dizer qual era a imagem que predominou naquela manifestação, nem mesmo sintetizar todas as linhas e posições que emergiram nos protestos de junho. Mas foi possível se aproximar e problematizar visões sobre esta realidade. No cenário das incertezas era necessário apropriar aquelas imagens, no curso de uma passeata, problematizar opiniões e duvidar das aparências, com o cuidado de não inibir nem desautorizar convicções audaciosas.

Nesse exercício foi possível observar a insatisfação generalizada com as instituições, incapazes de dialogar com a expectativa e os anseios entendidos como direitos pela população. Os desagrados eram tantos que, de fato, não caberiam num cartaz. As expressões eram múltiplas, e talvez, apontem para o desenho de um novo padrão, seja de informação, esclarecimento, educação ou cultura. Não será possível pensar um projeto democrático sem diálogo, sem alimentar um fluxo permanente de formação, informação e comunicação com a sociedade. A confusão e o desentendimento marcam os sentidos mais comuns da política. 
A julgar pelo que se viu numa grande cidade brasileira, a contestação não fez emergir apenas o velho discurso conservador contra a corrupção, tão saboreado pelas elites sempre empenhadas em virar o jogo contra a participação popular, apontando para portas de saída antidemocráticas. Sem dúvida essa é uma dimensão latente e perceptível no movimento, mas não se pode tomá-la como expressão central, menos ainda como dimensão unificadora dos protestos.

Em relação aos conflitos distributivos e às reivindicações por melhorias dos serviços públicos e repartição de renda, ficou evidente que elas seguem em blocos distintos das demandas por reconhecimento. Por um lado, afirmam-se os princípios de igualdade no acesso aos bens e serviços de qualidade, mas isso é expresso sem articulação com princípios democráticos de reconhecimento das diferenças. Os grupos que se organizaram, instituíram suas falas e produziram suas expressões, isolados na dimensão de suas próprias escolhas, talvez sem perceber que a articulação entre eles pode potencializar ambas as formas de luta por direitos. A exclusividade das bandeiras mostra a perspectiva desse desencontro, da escolha por caminhos próprios, dificultando a unidade e a percepção sobre as prioridades do movimento.

Ao retomar a perspectiva de Boaventura Sousa Santos (2007), podese dizer que não há lutas puras, e tomar as ações populares apenas nesse sentido, pode resultar em uma posição dogmática, insensível à dinâmica dos acontecimentos. É necessário cultivar a rebeldia, porém com "(...) vigilância epistemológica, teórica e política sobre os movimentos" (SANTOS, 2007, p. 73). Para regar e fazer crescer seu potencial libertário talvez seja necessário saudar a ação coletiva, observar seus limites, reconhecer e problematizar perspectivas corrosivas, evidenciadas na incompreensão do pluralismo, no desencontro das escolhas exclusivas e no menosprezo de alianças entre vítimas das formas de opressão. Se os obstáculos aos direitos estão na estrutura, nas relações sociais e na cultura, não há como removê-los, senão pela compreensão desses limites, pela afirmação de uma nova cultura, transformada em energia para ação de uma multidão disposta à emancipação. 


\section{Referências}

GOMES, R. "Em abril, falas mil". In: MARGATO, I.; GOMES, R. Literatura e Revolução. Belo Horizonte: Editora UFMG, 2011.

RANCIÈRE, J. A partilha do sensível: estética e política. São Paulo: Editora 34, 2009.

SANTOS, B. S. Renovar a teoria crítica e reinventar a emancipação social. São Paulo: Boitempo, 2007.

SILVERSTONE, R. Por que estudar a mídia? São Paulo: Loyola, 2002. 